\title{
Specific fitness training and testing in competitive sports
}

\author{
ERICH MÜLLER, ULRIKE BENKO, CHRISTIAN RASCHNER, and HERMANN SCHWAMEDER
}

Institute for Sport Sciences, University of Salzburg, A-5020 Salzburg, AUSTRIA

\begin{abstract}
MÜLLER, E., U. BENKO, C. RASCHNER, and H. SCHWAMEDER. Specific fitness training and testing in competitive sports. Med. Sci. Sports Exerc., Vol. 32, No. 1, pp. 216-220, 2000. Improvements of athletic capacity in high-performance sport are mainly achieved through an increase of the quality of training. In physical preparation, the quality of training can be improved by developing highly specific means of training. The aim of this paper is to present three examples of how highly specific means of fitness training of world class athletes can be developed. The first example presents a test profile of specific motor abilities of top class tennis players, the second one deals with the improvement of specific strength training methods for ski jumpers, and the third deals with the development of specific training devices of Alpine ski racers. Key Words: FITNESS TESTING, STRENGTH TRAINING IN SKI JUMPING, SPECIFIC TRAINING DEVICES, ALPINE SKI RACING
\end{abstract}

$\mathrm{T}$ The science of training will, more than ever before, be called upon to contribute to the optimization of training methods in high-performance sport. In the future, improvements of athletic capacity will probably be better achieved through an increase of the quality of training rather than an increase in the amount of training (11). In physical preparation, the quality of the training can be improved, above all, by using special technique-specific exercises and sport-specific tests. The literature of training science contains numerous studies which prove that the training of general conditioning, valid for all forms of sport, leads to considerable improvements of particular physical parameters. However, training of this kind hardly succeeds in increasing competitive capacity. On the other hand, it could be shown in many cases that the use of technique-specific means of training, parallel to general conditioning training, leads to considerable improvements of performance also among athletes with many years of training experience $(3,7,8,11-13,23,24)$.

It seems to be generally accepted that the adaptability of the organism rises with a reduction of the number of the factors to which it has to adapt, as we have to assume a relative limitation of adaptability reserves of the organism (1). Consequently, it is important to direct one's attention to the development of highly specific means of training.

For the realization of a training procedure that is highly orientated toward competition in a specific type of sport, the following conditions are necessary:

0195-9131/00/3201-0216/0

MEDICINE \& SCIENCE IN SPORTS \& EXERCISE ${ }_{\circledast}$

Copyright $(\underset{2}{2000}$ by the American College of Sports Medicine

Submitted for publication July 1997.

Accepted for publication March 1998.
- knowledge of the specific parameters relevant to performance in the specific sport or discipline,

- tests that fully cover the sport-specific parameters and that allow for the classification of test results, and

- training methods and exercises that fulfill the standard criteria for the specific means of training.

In the area of specific strength and power training, the "principle of dynamic correspondence" should be taken into consideration during the development of training exercises. This principle states that the special exercises must be in harmony with those parameters of movement that characterize the structure of competition technique $(5,10)$. A coordinative affinity between training and competition exercises has the advantage that it results in favorable training stimuli in the musculature relevant to the specific movement. It has the further advantage in that the specific neuronal mechanisms are developed, which improve the strength utilizability in concrete execution of movement, as defined by the technique-specific muscle innervation schema.

The aim of this paper is to present three examples of how we have tried to improve the quality of training of world class athletes. The first example deals with the development of a test profile of specific motor abilities of top class tennis players, the second with the improvement of specific strength training methods for ski jumpers, and the third with the development of specific training devices for Alpine ski racers.

\section{Development of a Test Profile of Specific Motor Abilities of Top Class Tennis Players}

As already mentioned at the beginning of this paper, the efficiency of the training depends considerably on the quality 
of training methods with respect to performance diagnostics available to the athlete. If possible, valid and standardized tests should be built into the training process for all performancerelevant features of the sport in question, especially in more complex sports like tennis and other game sports. The training plan must be organized to correspond to the results of these tests. Within the framework of long-term cooperation with the Austrian Tennis Association, we have developed a sport-specific test system for tennis players. The investigative methods applied here consist of the following steps:

Hypothetic selection of performance-related motor abilities. The motor abilities that hypothetically could be considered as being highly relevant for performance in tennis had to be singled out and ranked. These decisions could be based on already published results of studies, analyses of matches, and the judgments of experienced coaches and players. In a next step, appropriate tests had to be established to determine the degree of development of the selected motor abilities. As far as possible, already existing motor ability tests are used, in their absence, new ones have to be developed. The test procedure used included a total of 21 motor ability tests. Reliability and objectivity have been ascertained by retesting.

Examination of the relevance to performance of the chosen abilities. To find out whether the chosen motor abilities are really related to performance, 15 of the best male Austrian tennis players, aged between 16 and 18 yr, were asked to do the 21 tests. The results of these tests were correlated with the level of performance of these tennis players, using the rank-correlation analysis (2). If the correlations between the test results and the level of performance were statistically significant, the motor ability examined by the test was considered to be performance-related, and the respective test was considered to be a valid criterion. Seven of the 21 motor ability tests carried out proved to be of no relevance to performance. They were excluded from the further testing program.

Factor analysis of the performance-related tests. The performance-related tests were then put through a factor analysis in order to show the inner structure of the examined features and to make possible a basis for selecting individual tests for a test battery that would be as economical as possible. Factor analyses are used to split up the single characteristics into the lowest possible number of factors. In this process, the characteristics that are independent of others are separated, and those belonging together are assigned to one single factor (2) (see Table 1).

Specific test battery including norm profiles and norm tables. The test battery for measuring the most important tennis-specific motor abilities shown in the extracted factors consists of 10 single tests. All elite tennis players of the Austrian Tennis Association must take these tests twice annually, after which, a test profile is calculated for each person tested. As a result, the training schedule can be adjusted according to these results.

Figure 1 shows the motor performance level of T. M., No. 1 of the ATP ranking at the beginning of 1996, in the past $2 \mathrm{yr}$.
TABLE 1. From the 14 tests, the following three factors account for $93 \%$ of the total variance of the test characteristics: factor 1 contributes $49 \%$; factor $2,27 \%$; and factor $3,17 \%$.

\begin{tabular}{llc}
\hline & \multicolumn{1}{c}{ Test } & Loading \\
\hline Factor 1-Special agility in running & Shuttle run & 0.796 \\
& Side steps & 0.730 \\
& Hurdle-boomerang run & 0.599 \\
& Star jumping & 0.551 \\
Factor 2-Special power and strength & 20-m sprint & 0.703 \\
& Countermovement jump & 0.658 \\
& Hand grip & 0.654 \\
& Throwing the net ball & 0.626 \\
& Maximum strength: leg extensors & 0.594 \\
Factor 3-Basic and special endurance & 12-min run & 0.825 \\
& Shuttle run, 5 laps & 0.718 \\
\hline
\end{tabular}

\section{Ski Jumping Specific Strength Training}

The vertical take-off velocity, and therefore the jumping strength, is, as can be gathered from many scientific investigations, a central performance feature during ski jumping. The ski jumper has the task, from a deep in-run position at a knee angle of around $80^{\circ}$ within about $300 \mathrm{~ms}$, of jumping upward as powerfully as possible $(17,21)$.

Therefore, apart from general strength training in ski jumping, technique-specific strength training has become more and more important. Technique-specific strength training is mainly practiced by so-called simulation jumps. These are take-offs from a specific in-run position with the purpose of simulating the take-off motion on jumping hills as exactly as possible. There are many scientific studies dealing with this subject $(4,14-16,19,20)$.

Most of them conclude that movement patterns of the simulation jumps differ from those of the hill jumps to a large extent and suggest changing the technique of simulation jumps in order to get closer to the kinetic and kinematic structure of hill jumps.

In the present study, we have tried to improve the technique of simulation jumps. Up to that time, simulation jumps were mostly performed with training shoes and not with jumping boots. We tried to find out to what extent the use of jumping boots changes the structure of the simulation

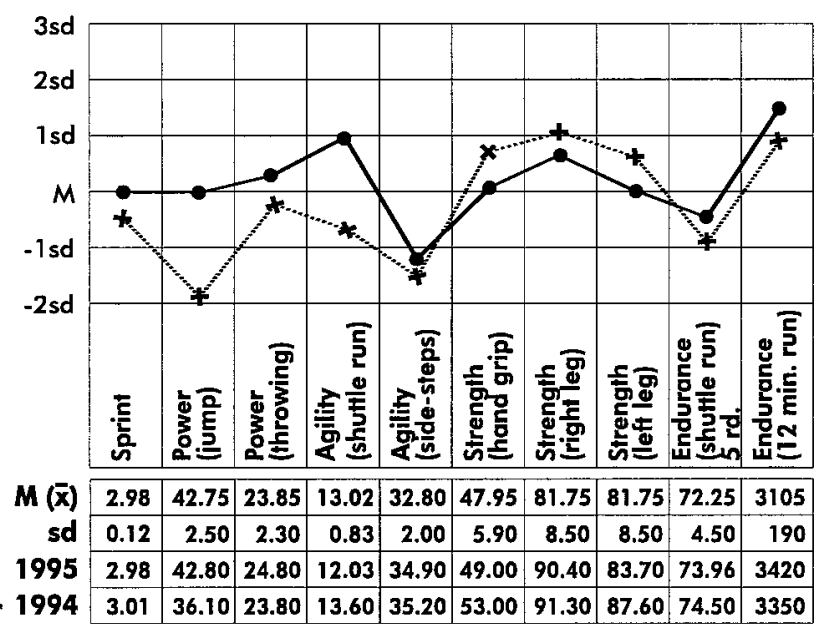

Figure 1-The test profile of T. M., a world class tennis player. 
jumps and whether it becomes more similar to the technique of hill jumps.

Nine ski-jumpers, all of them members of the Austrian National Team, took part in this investigation. They had to perform jump simulations on a force plate in a starting position similar to the in-run position in hill jumps. The heels were heightened by a wooden wedge. Every test person had to perform four jumps with training shoes and four jumps with jumping boots.

For determination of dynamic parameters, an AMTI (Newton, MA) force-plate $(200 \mathrm{~Hz})$ was used. In order to look at kinematic differences in the starting position, video recordings $(50 \mathrm{~Hz})$ were evaluated two dimensionally. For the determination of the activity of the gastrocnemius muscle while subjects wore different types of footwear, electromyographical methods were used (Biostore, $1000 \mathrm{~Hz}$, Frankfurt, Germany).

The vertical and horizontal anterior-posterior components of the forces were measured to determine the parameters jumping durance (t), resultant take-off velocity (v), and power capacity defined as the maximum of the grade (Fex). The starting positions were determined by calculating the hip- (a), knee- (b), and ankle-angles (g) by means of a three-segment model consisting of upper body, thigh, and shank.

The statistical differential testing was conducted using ANOVA method. The results are shown in Table 2.

With respect to the starting position, represented by the angle at the hip- (a), knee- (b), and ankle-joint (g), no significant difference appears between the two series of attempts, meeting the prerequisites for a comparison. With the exception of the hip angle, which is somewhat greater during the hill jump, these values largely correspond to the hill-jump position $(17,20)$. While subjects wore training shoes, the take-off duration was $16 \mathrm{~ms}$ longer $(+4.8 \%)$ and the take-off velocity $0.13 \mathrm{~m} \cdot \mathrm{s}^{-1}$ greater $(+4.3 \%)$ in comparison with the jump with jumping boots. The differences are each significant. Regarding power capacity, the differences were coincidental $(-5.4 \%)$. Because the power capacity is mainly caused by the hip- and knee-extensors, it is largely unaffected by the type of footwear used, which seems quite plausible.

Through the limited plantar flexion in the jumping joint using jumping boots, the significant differences with respect to take-off duration and take-off velocity can be explained. In order to test this supposition, the gastrocnemius muscle

TABLE 2. Kinematic and kinetic take-off parameters; comparison of jumps with jumping boots and training shoes; values are (mean \pm SD).

\begin{tabular}{lcccc}
\hline Parameter & Jumping Boots & Training Shoes & $\%$ & $\boldsymbol{P}$ \\
\hline$\alpha\left[^{\circ}\right]$ & $22.7 \pm 4.7$ & $23.9 \pm 4.9$ & & \\
$\beta\left[^{\circ}\right]$ & $78.4 \pm 3.3$ & $79.9 \pm 3.6$ & & \\
$\gamma\left[^{\circ}\right]$ & $53.3 \pm 2.6$ & $52.9 \pm 2.9$ & & \\
$\mathrm{t}[\mathrm{s}]$ & $0.333 \pm 0.020$ & $0.349 \pm 0.028$ & +4.8 & $\star \star$ \\
$\vee\left[\mathrm{m} \cdot \mathrm{s}^{-1}\right]$ & $3.05 \pm 0.17$ & $3.18 \pm 0.15$ & +4.3 & $\star \star$ \\
Fex $\left[\mathrm{kN} \cdot \mathrm{s}^{-1}\right]$ & $5.9 \pm 2.2$ & $5.6 \pm 2.0$ & -5.4 & \\
\hline
\end{tabular}

*** Significant at $P<0.01$.

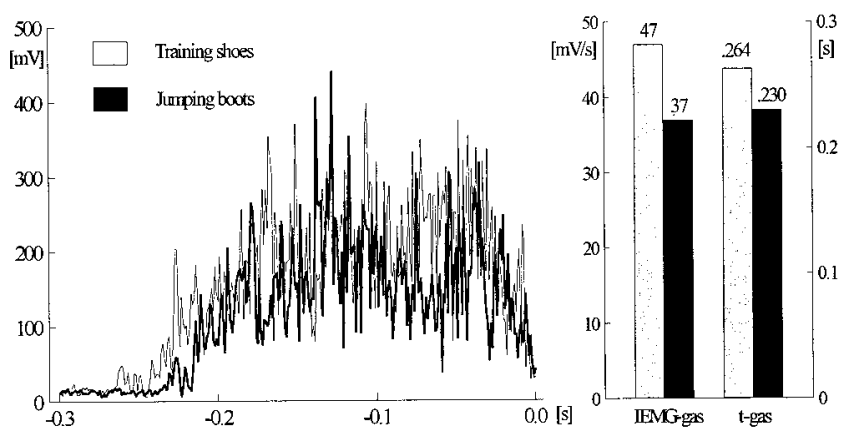

Figure 2-Synchronized electromyograms, strength and duration of the gastrocnemius muscle; comparison between jumps with training shoes and jumping boots.

was deduced electromyographically under the conditions described. Figure 2 shows synchronized electromyograms and values of the IEMG under both conditions. The averaged value of the five attempts are shown for each $(t=0$ refers to the time of take-off).

It should be recognized that the duration (t-gas) as well as the strength of the utilization of the gastrocnemius muscle (IEMG-gas) while subjects are wearing training shoes turns out significantly greater.

Obviously, the jumping technique depends on the footwear used, and therefore the use of jumping boots is an essential requirement for the technique-specific training in ski jumping.

\section{Development of Specific Training Devices for Alpine Ski Racers}

The necessity of using highly specific means of training mainly applies to what are called seasonal sports such a Alpine ski racing. Alpine ski racing is one of those sports that makes high demands on technical and physical abilities. This is made even more difficult by the fact that techniquespecific training can only be performed on snow. Because of the fact that snow-training in summer is very problematic due to organizational and financial reasons, technique-specific training is highly important $(9,18,22)$.

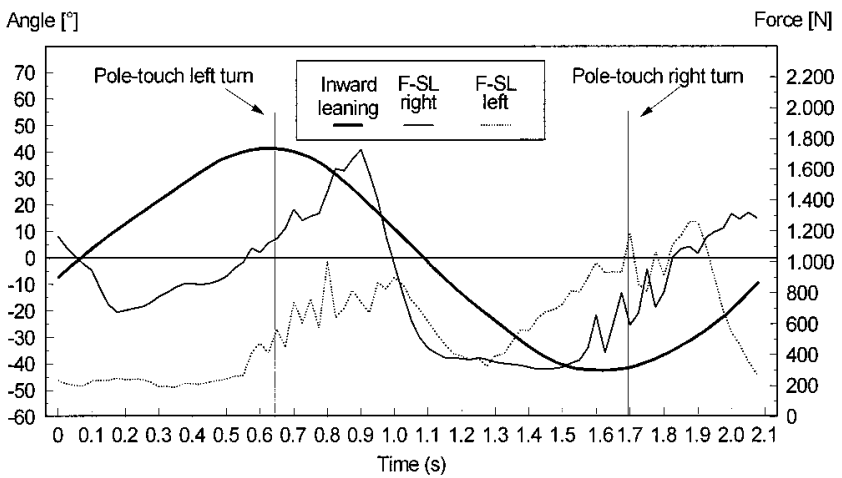

Figure 3-Ground reaction forces and the inward leaning angle of the skier during a left and a right slalom turn. 


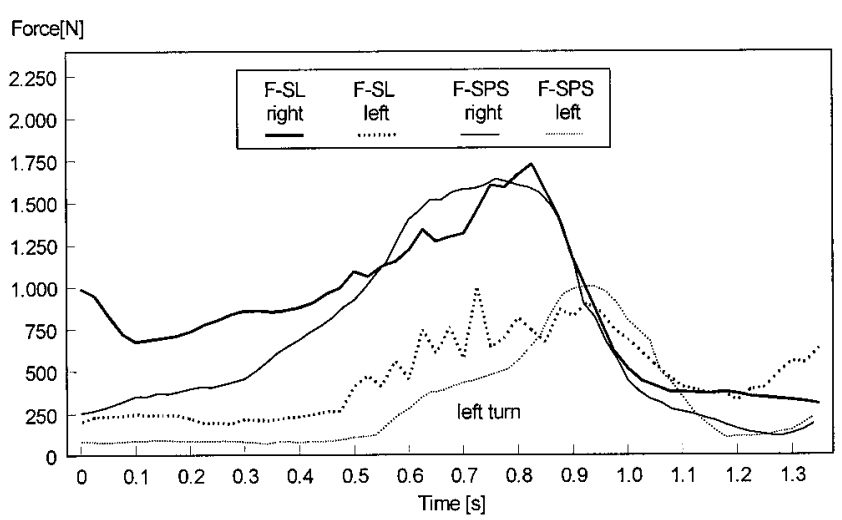

Figure 4-Ground reaction forces of a top class skier during a slalom turn and during a slalom imitation exercise on the ski power simulator (SPS).

In this study, we have tried to develop training devices that make possible the performance of slalom-specific simulation exercises. These exercises should come very close to the kinetic and kinematic structure of slalom technique.

As a basis for the development of ski-racing-specific simulation exercises, a detailed kinematic and kinetic analysis of modern slalom technique was necessary. As test persons, six members of the Austrian senior and junior national teams were at our disposal. They were asked to complete a slalom course with openly planted gates. The slalom slope was the equivalent of the usual standard for World Cup competitions.

For the kinematic analysis, the course was marked with 30 different high rigid calibration poles. The three-dimensional coordinates of each of the reference markers and the coordinates of the calibration points on a Peak Performance (Englewood, CO) calibration frame, placed approximately in the center of the course, were obtained using a theodolite and standard surveying methods. The calibration frame was used to aid accurate computation of the internal camera orientations and direct linear transportation parameters.

Two video cameras mounted on platforms (recording frequency $50 \mathrm{~Hz}$ ) could follow the racer in his movements through panning on one hand and, on the other, could guarantee a full-size picture of the test person from start to finish through the use of a zoom lens. This has a positive impact on the exactitude of the measurements in the following evaluation using the peak three-dimensional software and the panning program development by Drenk (6). Drenk developed a computer program based on Peak software, which enables the user to obtain the three-dimensional data of the body landmarks by using panned, tilted, and zooming cameras (panning-program). If the filming conditions are strictly adhered to, the algorithms underlying the panning-program guarantee the usual accuracy of fixed cameras in the whole range of filming.

The ground reaction forces and pressure distributions on the plantar surface were measured with the Emed System from Novel (Munich, Germany). The racers had to ski with two specially adapted insoles with 85 capacitive sensors,

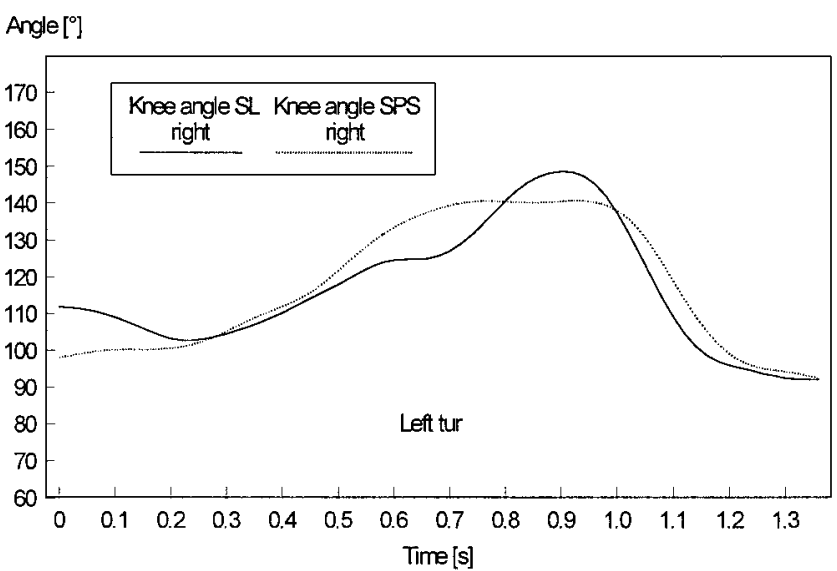

Figure 5-Right knee angle of a top class skier during a slalom turn and during a slalom imitation exercise on the ski power simulator (SPS).

placed between inside boot and plantar surface. The data were collected in the mikro-EMED (Munich, Germany), worn in a specially adapted belt around the skier's waist. The sampling was $40 \mathrm{~Hz}$.

The results of these measurements can be presented in a large number of selected kinematic and kinetic parameters. As an example, Figure 3 shows the ground reaction forces of the outside and the inside leg and the inward leaning angle of the racer during a left and a right turn.

During the left turn, the maximum force on the outside leg is about 2.5 times body weight, and the one on the inside leg about 1.5 times body weight. The maximum of the inward leaning angle is $40^{\circ}$, and it is reached at the time when the pole is touched by the outside hand.

In the second part of this study, two training devices were developed, based on the knowledge gained from the results of the slalom analysis. The goal was to realize the highest possible correspondence between the characteristics of slalom competition and training exercises. In this paper, one of the two devices, the so-called ski-power simulator, was introduced.

To check the validity of the training exercises that can be performed on the ski-power simulator, the same kinematic and dynamic measurements have been done as for the slalom analysis. Figure 4 compares the ground reaction forces of a top class skier during a slalom turn with those of a slalom imitation exercise on the ski power simulator. This example indicates the similarity of the kinetic structure of the simulation exercise on the ski power simulator with the slalom performance on the slope (Fig. 5).

Ski power simulator demonstrates the imitation exercises that fulfill the demand for structural similarity with the slalom technique to a great extent. This training device will probably be able to improve the efficiency of training in Alpine ski racing in the near future.

Address for correspondence: Dr. Erich Müller, Institute for Sport Sciences, University of Salzburg, Akademiestraße 26, A-5020 Salzburg, Austria. E-mail: erich.mueller@sbg.ac.at. 


\section{REFERENCES}

1. Boiko, V. V. The human development of movement abilities (Die gezielte Entwicklung der Bewegungsfähigkeiten des Menschen), Moskau 1987, partly translated in: P. Tschiene, Die neue "Theorie des Trainings" und ihre Interpretation für das Nachwuchstraining. Leistungssport 1: 11-17, 1989.

2. BortZ, I. Statistik. Berlin: Springer Verlag, 1993, pp. 753.

3. Bosco, C. Physiological observations of explosive strength training under super-heavy strength conditions (Physiologische Betrachtungen zum Explosivkrafttraining unter Hyperschwerkraftbedingungen). Leistungssport 2:19-24, 1985.

4. Dillmann C., K. Campbell, and I. Gormley. Force-platform testing of ski jumpers. United States Ski Coaches Association 4:3538, 1980.

5. Duatschkow, W. M. Optimization and Guidance of Training Processes (Die Steuerung und Optimierung des Trainingsprozesses). Berlin: Bartels \& Wenitz KG, 1977, pp. 100.

6. Drenk, V. Measurement of movable and adjustable cameras (Bildme $\beta$ verfahren für schwenk- und neigbare sowie in der Brennweite variierbare Kameras). In: Institut für Trainingswissenschaft 1:130-142, Berlin, 1994.

7. Hakkinen, K., and P. Komi. Changes in electrical and mechanical behaviour of leg extension muscles during heavy resistance strength training. Scand. J. Sport Sci. 2:55-64, 1985.

8. Harre, D., and M. Hauptmann. Strength abilities and strength training (Kraftfähigkeiten und Krafttraining). Theorie und Praxis der Körperkultur 3:205-213, 1983.

9. LINSER, F. Effective Strength Training (Effektives Krafttraining). Wiesbaden: Limpert Publishers, 1994, pp. 232.

10. Menzel, H. I. Kinematic affinity of training and competitive throws in javelin (Kinematische Affinität von Trainings- und Wettkampfwürfen im Speerwurf). In: Sport Research Articles (Forschungsgegenstand Sport), H. J. Menzel and R. Preiss (Eds.). Frankfurt: Thun \& Deutsch, 1990, pp. 237-256.

11. Müller, E., and E. WAChter. Training methods for improvement of specific jumping-power in ski jumpers (Trainingsmethoden zur Verbesserung der speziellen Sprungkraft von Skispringern). Spectrum der Sportwissenschaft 1:47-71, 1989.

12. Rutherford, O. M., and D. A. Jones. The role of learning and coordination in strength training. Eur. J. Appl. Physiol. 55:100105, 1986.
13. SAle, D. G. Neural adaption to strength training. In: Strength and Power in Sport, P. V. Komi (Ed.). Oxford: Blackwell Scientific Publications, 1993, pp. 249-265.

14. SASAKI, T., and K. TsunODA. Analytical study of take-off action in ski-jumping. Hokkaido J. Phys. Educ. 23:13-19, 1988.

15. Sasaki, T. K. Tsunoda, and E. Ucidda. The effect of segment power in ski jumping. In: Abstract Book of the XIVth Congress of the International Society of Biomechanics. Paris: International Society of Biomechanics, 1993, pp. 1186-1187.

16. Schmidtbleicher, D. Motor conditions and strength (Motorische Beanspruchungsform Kraft). Dtsch. Z. Sportmed. 9:356-377, 1987.

17. Schwameder, H., and E. Muller. Biomechanical description and analysis of the V-technique in Ski jumping (Biomechanische Beschreibung und Analyse der V-Technik im Skispringen). Spectrum der Sportwissenschaften 1:5-36, 1995.

18. TESCH, P. A. Aspects on muscle properties and use in competitive Alpine skiing. Med. Sci. Sports Exerc. 27:310-314, 1995.

19. Tveit, P., and P. O. Pedersen. Forces in the take-off in ski jumping. In: Biomechanics VII-B, A. Morecki, et al. (Eds.). Baltimore: University Park Press, 1981, pp. 472-477.

20. Vaverka, F., M. Janura, M. Elfmark, J. Salinger, and M. MCPHERson. Inter- and intra-individual variability of the skijumper's take off. In: Science and Skiing, E. Müller, E. Kornexl, and H. Schwameder (Ed.). London: E \& FN Spon, 1997, pp. 61-71.

21. Schwameder, H., E. Müller, C. Raschner, and F. Brunner, Aspects of technique-specific strength training in ski-jumping. In: In: Science and Skiing, E. Müller, E. Kornexl, and H. Schwameder (Ed.). London: E \& FN Spon, 1997, pp. 309-319.

22. WerschoshanskiJ, J. W. Longitudinal and delayed training effect of specific strength training (Der langfristig verzögerte Trainingseffekt durch konzentriertes Krafttraining). Leistungssport 3:4142, 1984.

23. WerschoshanskiJ, J. W. Effective training (Effektiv Trainieren). Berlin: Sportverlag, 1988, pp. 167.

24. Zatsiorsky, V. M. Strength Training-Theory and Practice (Krafttraining-Wissenschaft und Praxis). Aachen: Meyer \& Meyer, 1996, pp. 287. 